\title{
COMPARATIVE ANALYSIS OF REACTIVE ENERGY REGULATIONS
}

\author{
Arvids Jakusenoks, Aigars Laizans \\ Latvia University of Life Sciences and Technologies, Latvia \\ arvids.jakusenoks@gmail.com, aigars.laizans@llu.lv
}

\begin{abstract}
The article represents the analysis of tariffs, penalties and costs introduced for reactive electrical energy in different European countries. European electrical power suppliers' websites and scientific articles were overviewed for information about reactive electrical energy regulations and tariffs. Reactive electrical energy penalties are introduced by the network operators in order to encourage the electricity users to reduce reactive energy produced by them impact to the electric energy supply network properties. As the trend in the reactive electrical energy goes from inductive towards capacitive, because of electrical appliance modernization through the increased use of LED light sources and invertors in the energy supply chain from the grid to the device, the need for the world experience analysis occurred. The research shows that several countries in Europe applied penalties on the reactive electrical energy production not only for heavy users (users with big allowed electrical power), but also for households. The reason seems to be increased proportion of reactive energy production from low voltage electricity users, including household and small business units. The measurements and accounting of reactive energy ask for special electric energy meters, which is the additional cost either to the consumers or to the electric network operator. At the same time large part of European countries do not have any regulations regarding reactive electrical energy, just some of them introduced the mentioned regulations for medium-voltage or high-voltage electricity users. With the reactive electric energy component increase there is high probability that the regulations and penalties will be introduced on a much wider scale, and will include low-voltage powered households as well, especially with the reduced electricity consumption per capita, and increasing operation costs incurred in the budget of network operators.
\end{abstract}

Keywords: reactive, energy, fee, tariff, low-voltage, regulation.

\section{Introduction}

Previous studies in the household sector showed how the share of reactive electricity in it is significant, it increases year after year, and the character changes from inductive to capacitive [1]. Due to reactive energy increase in low voltage network, all electrical networks become less stable and even large-scale power interruptions can be observed. The recent Northeast blackout in the United States (in 2003), which affected 50 million users of electrical power supply can be mentioned as the biggest crash, which occurred due to the rise of reactive energy [2]. The studies must be carried out as to reactive power compensation and limitations, as well as the reactive energy measures that will allow the power grid operators to decrease losses and gain higher stability of energy supply [3].

Reactive electrical power problem is well known for electrical power researchers by known disturbances on electrical power grid. Reactive electrical power compensation is provided in industrial sector because of big taxes for generated or consumed electrical energy. These reactive electrical energy taxes encourage industrial sector consumers to reduce the consumed and generated reactive electrical energy by compensation. Industrial sector is much interested in reactive electrical power compensation procedures, because reactive electrical power compensation equipment investments repay over several years due to the real high amount and taxes for consumed and generated reactive electrical power.

Low-voltage, household and small consumers in several countries are not interested to invest money in reactive electrical power compensation equipment, because they do not have such taxes, or (in several countries) consumption and taxes are low and do not pay off.

Due to the fact that the EU announced the intention to connect all EU countries in one electric energy supply grid, the regulation of all components must be equalized based on the scientifically and economically proven data and the norms and regulations established. Currently each EU country has its own approach to the reactive energy, and the current research tries to analyse the reasons behind the decisions made, in order to offer the model, which could be applied in all EU.

The EU countries, where the reactive electrical power problem was developed, responsible instances and/or electrical power companies invented taxes, tariffs or fees for consumed and generated reactive electrical power. Such tax practice is also applicable in many other countries of the world (such as Singapore [4], Philippines [5], India [6], the USA, etc.). 


\section{Materials and methods}

The research was provided using the open data from electric energy suppliers and electric energy network operators in the EU countries. The research revealed also the countries, which did not disclose this information due to confidentiality of agreements, which is not good practice, and allows for inequality between customers.

The basic principle observed to be used by the EU countries in the electric energy quality area is the application of the European Standard EN50160 [7], which includes the following issues:

- electric power system frequency;

- magnitude of the supply voltage;

- magnitude of the rapid voltage changes;

- flicker severity;

- supply voltage dips;

- short interruptions of the supply voltage;

- long interruptions of the supply voltage;

- supply voltage unbalance;

- harmonic voltage.

The majority of the topics included for the monitoring are directly connected with reactive energy produced in the electric network by the consumers. Through the countries regulation, which monitors the energy quality indirectly, it also monitors the reactive component of energy.

Information about the reactive energy penalties is included in the electric energy consumption payment policy. Only just few countries mentioned this directly as a penalty, introducing the allowed limits and levels, what can be produced without penalties, but other countries introduced the reactive energy compensation costs into the main payment for electric energy. This information is available on the ENSTO-E overviews and on the power supplier company's websites.

The large part of information was received through the European Network of Transmission System Operators (ENTSO-E), which represents 43 European electricity transmission operators [8].

\section{Results and discussion}

The data analysis revealed that $12 \mathrm{EU}$ countries do not have any regulations and penalties as to reactive energy production and supply to the electric network. These countries are Austria, Bosnia and Herzegovina, Cyprus, the Czech Republic, Denmark, Great Britain, Greece, Hungary, Luxembourg, Netherlands, Slovakia and Sweden [9]. At the same time the analysis showed that several countries introduced the regulations with the extensive growth of smart grids in their countries (Italy, the network operator Terna, and Germany, electric energy supplier $50 \mathrm{~Hz}$ ) [10]). Few countries (Belgium and Croatia) have introduced the penalties for reactive electric energy at the medium voltage and high voltage networks, with no regulations for low voltage (household) electric energy consumers [9]).

As opposite to the majority of the EU countries, Latvia introduced the regulations and penalties on the reactive energy. The calculation of the penalty amount is based on several criterions, and the payment principles had been approved by the Cabinet of Ministers of Latvia [11].

Historically, reactive electricity charges were introduced from 1995 [12], and charged by the only electric energy supply and network owning state electricity company JSC Latvenergo. Initially the penalties for both types of reactive energy were equal. Subsequently, due to new tariffs for electricity introduced in 2009 [13], the tariffs were changed also for the reactive electric energy - the charge was split, where the charge for capacitive reactive energy was established as 3 times higher than for inductive reactive energy. This regulation was in power until 2011 [14], but since Latvia joined euro currency pool (disclosed use of national currency lats), in 2014 the re-calculation of these fees was made according to the exchange rate established by the Bank of Latvia at 0.702804 LVL (Latvian lats) per 1 EUR [15]. In 2014 [11] new regulations as to electric energy were adopted in Latvia, where no charges for reactive electricity were used (Figure 1). 


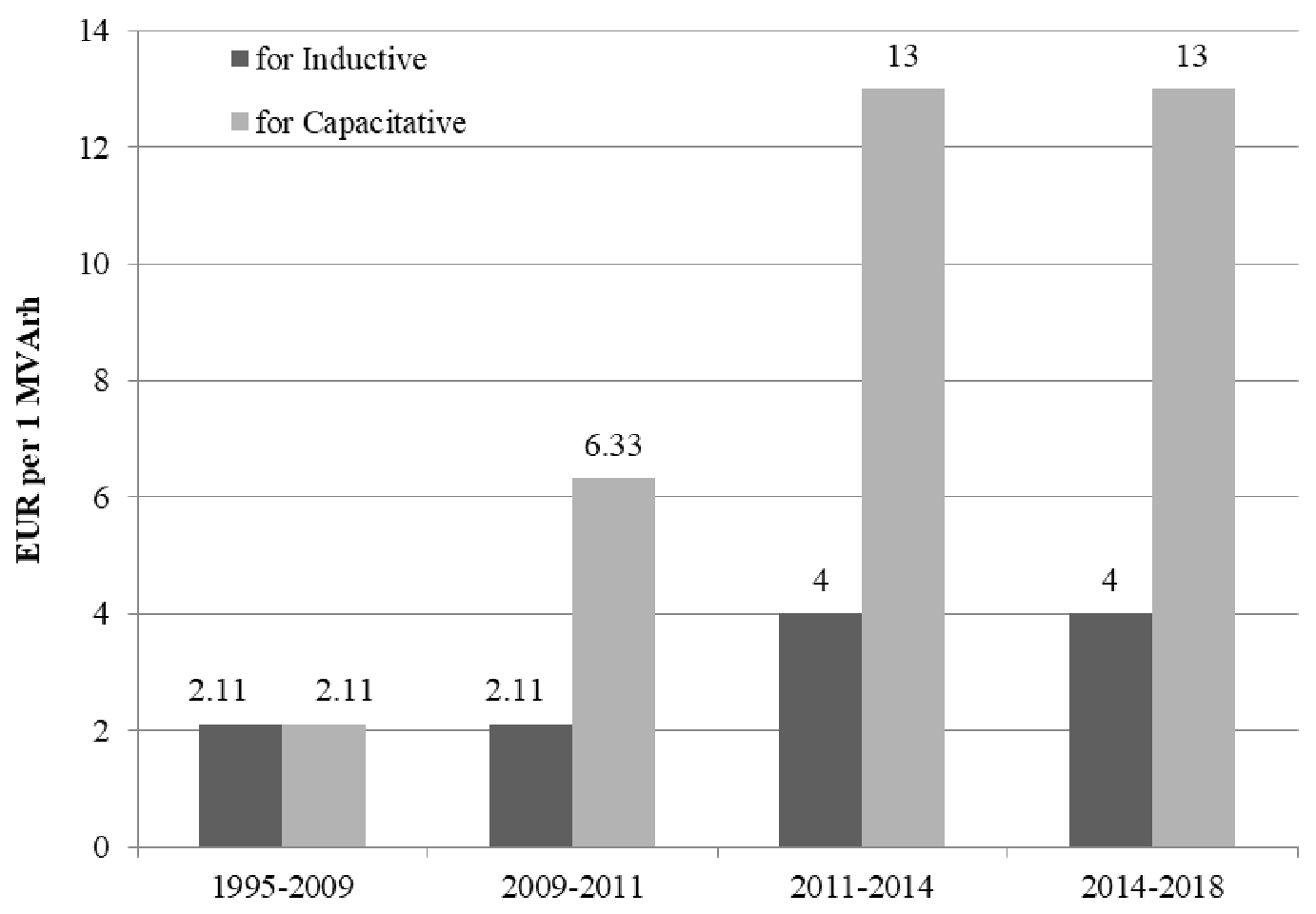

Fig. 1. Changes in reactive energy penalties - historical data, Latvia

The criterions of penalty application are based on the character of the reactive energy (differentiation between inductive and capacitive reactive energy production penalties), and on the overall electric energy consumption (current based limitation - e.g., current input is higher than 200A). The application of penalties takes place when:

1. Inductive reactive energy supplied to the electric network, if $\cos \varphi<0.929$ (and $\operatorname{tg} \varphi>0.4$ ). The penalty is 4 EUR per 1 MVArh.

2. Any amount of capacitive reactive energy supplied to the electricity network. The penalty is 13 EUR per 1 MVArh.

In order to account for the reactive energy, the four quadrant electric energy meters [16] are being introduced by the network operator JSC "Sadales tîkls", and the receipt including both active energy costs and penalties for the reactive energy is being issued on monthly basis.

The low voltage electric energy supply grids are less regulated as to the reactive energy (even in Latvia there are no regulations and penalties for household), but with the changes in the electric appliances and the consumption trends, deepened research was done there.

In many of the analyzed countries there was a shift in reactive electricity tariffs; the aspects of changes and even the reasons of the reactive energy regulation introduction are unknown. The biggest changes occurred in Lithuania, Northern Ireland, Slovenia and Serbia.

In Slovenia, according to the ENTSO-E data, the reactive electricity tariff was not subdivided into inductive (reactive) reactive power and reactive (generated) reactive power, which resulted in a change in tariffs in 2016. The sum of the spent reactive electricity was broken down into spent (inductive reactive) and generated (capacitive reactive) electricity on equal parts, and a slight increase of tariff (by 0.17 EUR per 1 MVArh) took place in 2017.

There was no reactive electricity tariff in Northern Ireland, but starting with 2015 the penalty tariff is 0.31 EUR per 1 MVArh, and it is equal for inductive and capacitive reactive electric energy. The largest change in the tariff for reactive electricity occurred in Serbia [17].

The results of the analysis of regulations and penalties for low-voltage network in different EU countries are presented in Table 1. 
Table 1

Reactive energy for low voltage consumers regulations and penalties in different EU countries

\begin{tabular}{|c|c|c|c|}
\hline \multirow{2}{*}{ Country } & \multirow{2}{*}{ Limits } & \multicolumn{2}{c|}{$\begin{array}{c}\text { Tariff/Penalty, EUR per } \\
\text { 1 MVArh }\end{array}$} \\
\cline { 2 - 4 } & & for inductive & for capacitive \\
\hline \multirow{2}{*}{ Latvia [11] } & if 200A or more and $\operatorname{tg} \varphi>0.4$ & 4 & 13 \\
\cline { 2 - 4 } & if 200A or more & - & 13 \\
\hline Lithuania [18] & $\begin{array}{c}\text { for each consumer, } \cos \varphi< \\
0.95\end{array}$ & 0.71 & 1.42 \\
\hline $\begin{array}{c}\text { FYROM (Former Yugoslav } \\
\text { Republic of Macedonia) }\end{array}$ & $\cos \varphi<0.95$ & 0.14 & 0.14 \\
\hline Northern Ireland [19] & for all $\operatorname{consumers,~} \cos \varphi<0.95$ & 0.31 & 0.31 \\
\hline Serbia [17] & $1<\cos \varphi=0.95$ & 1.3938 & 1.3938 \\
\cline { 2 - 4 } & $\cos \varphi<0.95$ & 2.7876 & 2.7876 \\
\hline Slovenia [9] & $\cos \varphi<0.95$ & 3.1 & 3.1 \\
\hline Estonia [20] & if $63 \mathrm{~A}$ and $\operatorname{more}, \operatorname{tg} \varphi>0.15$ & 0.54 & 0.76 \\
\hline
\end{tabular}

The results of the analysis are presented in Figure 2 and Figure 3.

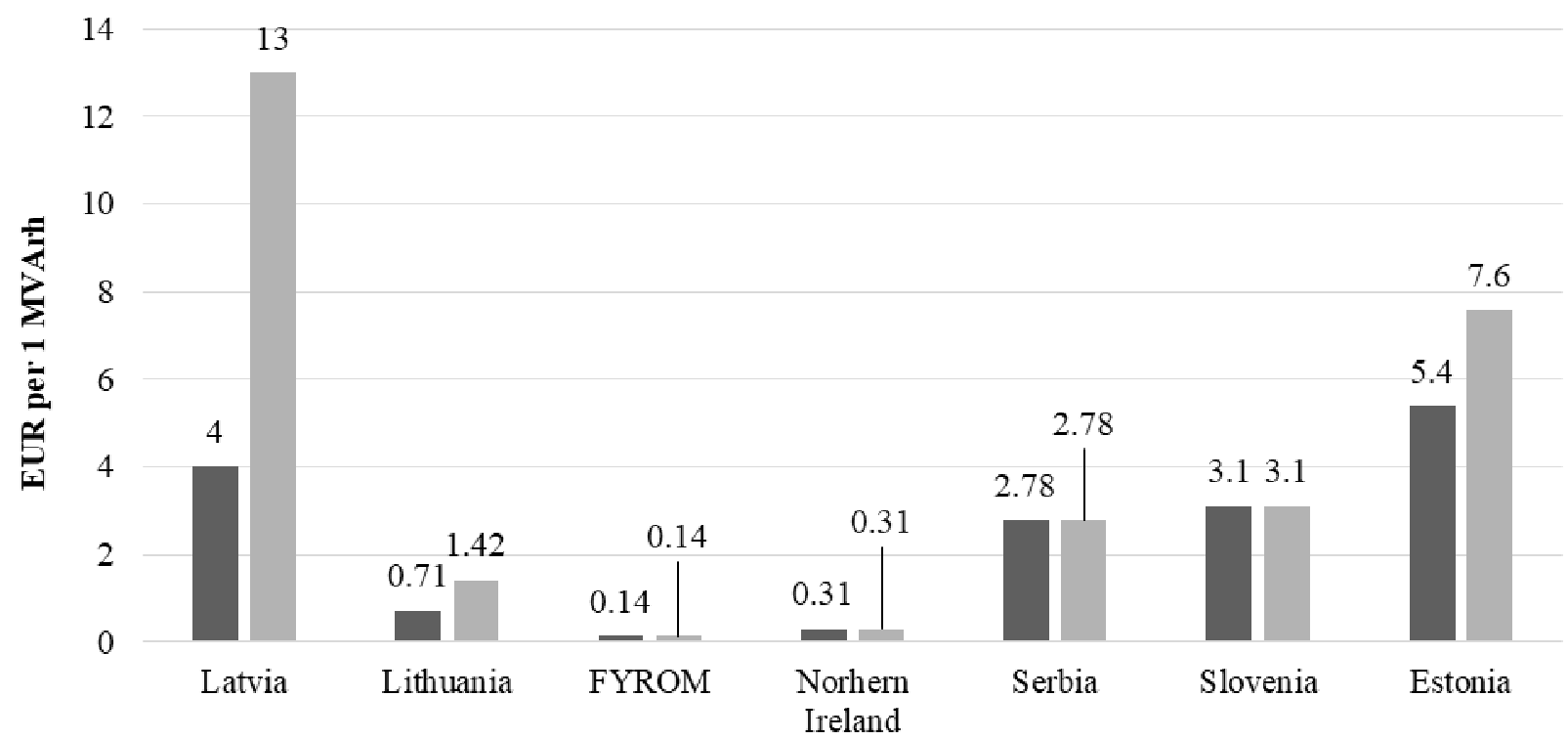

- Tariff/Penalty, EUR per 1 MVArh for inductive $₫$ Tariff/Penalty, EUR per 1 MVArh for capacitative

Fig. 2. Penalties for reactive electrical energy at $\cos \varphi<0.95$, by countries, 2017

As the graphs in Fig.3 show, the largest penalty for reactive energy spending in the electric network is being used in Latvia, followed by Estonia and Slovenia. Lithuania recently introduced tariffs for reactive component in the consumed electric energy for all consumers, although the fee is rather small.

The introduction of different additional fees and tariffs took place also after all EU partner countries, including Latvia, had to introduce the Third Energy Package (EU Third Energy Package), which requested to unbundle the electric energy business. Separate companies had to operate in electric energy production, distribution and network operation. This allowed also to unbundle the cost structure, separating expenses and profits in each electric energy business stage. This also asked each business unit to have normalized profit, also including all related expenses. 


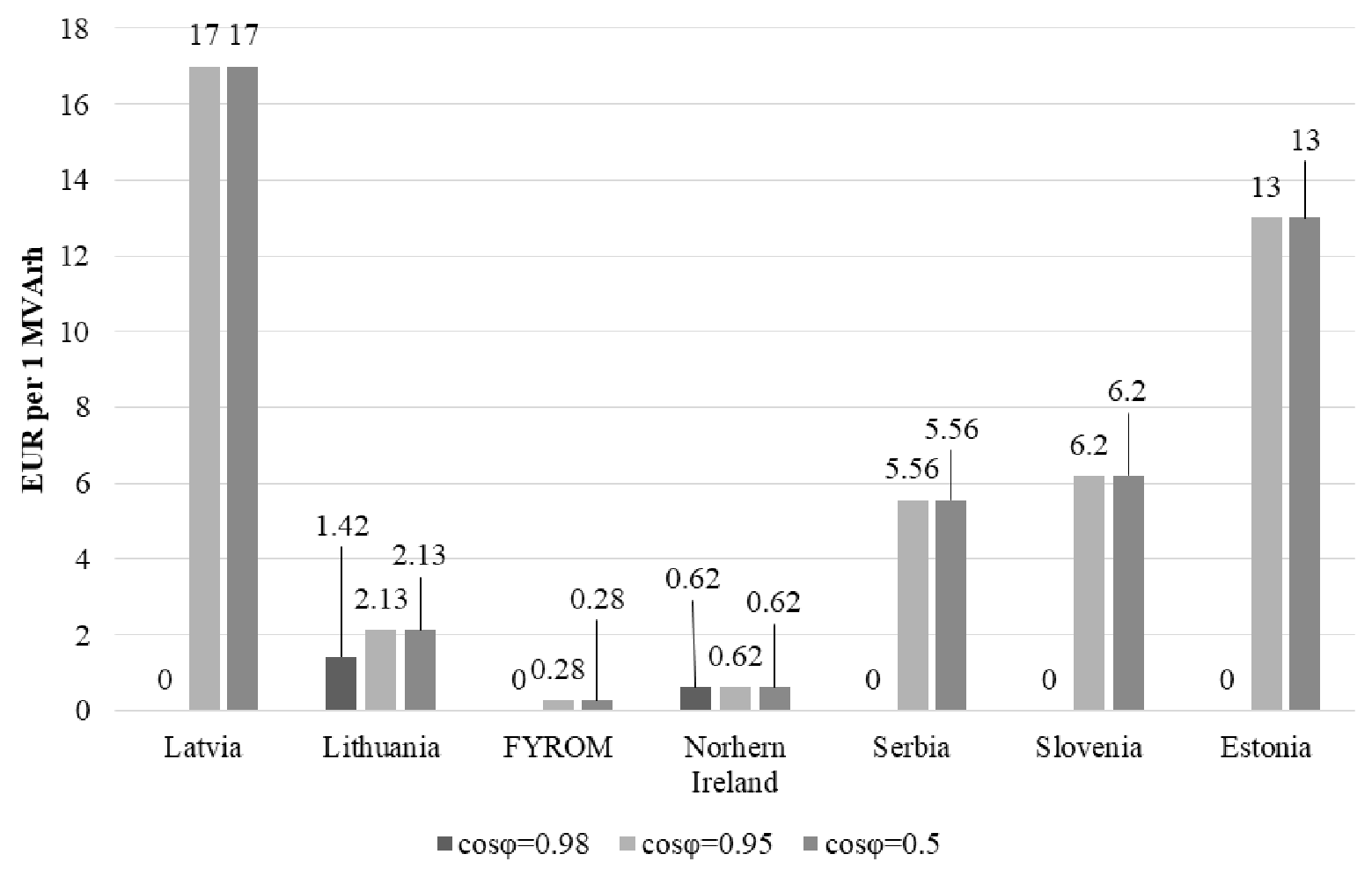

Fig. 3. Dependence of penalties on power factor, by countries, 2017

This business model change has led to the situation, where the network operators were overlooking all perturbances to their electric network operation conditions and are trying to include all quality diminishing factors, which are created by the consumers, especially reactive energy related, as the expenses to be covered by the consumers themselves. This trend is being seen by the slow but steady increase in the network related costs part in the final bill for the customer.

\section{Conclusions}

1. The comparative analysis of the trends in the EU countries approach to the reactive energy regulation in the electric energy supply and consumption leads to the following conclusions:

2. Interconnected EU level electric energy supply network will require joint regulation of all aspects of electric energy quality, including commonly applied unified regulations and penalties for reactive energy.

3. Increase of reactive component in the electric energy consumed will lead to the increased penalties, because the reactive energy decreases the quality of electric network operations, and asks for additional investments, which will (with high probability) lead to the increased portion of costs related to the network operations in the final electricity bills for customers.

4. Although the household does not pay for the reactive energy component currently, the recent trends allow to state with high probability that this consumer segment will also be involved in reactive energy related costs coverage.

5. This in addition will lead to the changes in the requirements for the household electric appliances - producers will be asked to inform about the reactive component delivered by their devices, and also will be asked to produce the equipment with high power factor (higher than 0.95).

\section{References}

[1] Jakusenoks A., Laizans A. Household electric power supply grid power factor trends. Proceedings of the 14th International Scientific Conference "Engineering for rural development", 2015, pp. 355-360.

[2] Gilstrap M., Amin S., Decoria-Souza K. United States Electricity Industry Primer, 2015, pp. 1-94. 
[3] Jakusenoks A., Laizans A. Reactive electrical power compensation in household sector. Proceedings of 16th International Scientific Conference "Engineering for rural development", 2017, pp. 1151-1156.

[4] Singapore Power Services. Electricity tariff revision for the period 1 January to 31 March 2017. 2017, pp. 3-6.

[5] CATIF-USAID. Challenges in pricing electric power services in selected ASEAN countries Philippines climate change and clean energy. 2013, p. 189.

[6] Maharashtra electricity regulatory commision. Maharashtra electricity regulatory order ( SUOMOTU ). 2013, pp. 1-113.

[7] Standard EN 50160 - Voltage characteristics of electricity supplied by public distribution systems. 2010.

[8] European Network of Transmission System Operators for Electricity. [Online] [16.03.2018]. Available at: https://www.entsoe.eu/Pages/default.aspx.

[9] Jaeger S., Vervaecke A., Beuger L., ENTSO-E Overview of Transmission Tariffs in Europe: Synthesis 2017. Izabela Netkova Gro Ballestad, 2017, p. 68.

[10]ENTSO-E. Reactive power management at T - D interface ENTSO-E guidance document for national., 2016, p. 14.

[11]Cabinet Ministers of Latvia, "Regulations Regarding the Trade and Use of Electricity," Regulation No50., 2014. [Online]. Available: https://likumi.lv/ta/en/id/263945-regulationsregarding-the-trade-and-use-of-electricity. [Accessed: 08-Mar-2018].

[12] Cabinet Ministers of Latvia, "Regulations for electricity trading price," 1995. [Online] [08.03.2018]. Available at: https://likumi.lv/ta/id/37358-noteikumi-par-elektroenergijaspardosanas-cenam.

[13] Cabinet Ministers of Latvia, "Regulations Regarding the Trade and Use of Electricity," 2009. [Online] [08.03.2018]. Available at: https://likumi.lv/ta/id/195356-elektroenergijas-tirdzniecibasun-lietosanas-noteikumi.

[14] Cabinet Ministers of Latvia, "Regulations Regarding the Trade and Use of Electricity," 2011. [Online] [08.03.2018]. Available at: https://likumi.lv/ta/id/241279-elektroenergijas-tirdzniecibasun-lietosanas-noteikumi.

[15] "Press releases - Bank of Latvia," 2013. [Online] [08.03.2018]. Available at: https://www.bank.lv/en/component/content/article/596-for-media/press-releases/8619-parneatsaucami-fiksto-lata-prejas-kursu-uz-eiro? Itemid $=201$.

[16] "Elgama-electronika" Ltd. EPQS Multifunction Meter of Active, Reactive and Apparent Electric Energy. Vilnius, 2007, p. 36.

[17]Energy agency of the Republic of Serbia. [Online] [06.03.2018]. Available at: https://www.aers.rs/Index.asp?l $=2 \& \mathrm{a}=21.05 \& \mathrm{tp}=$ TarifeEE\#EPS.

[18]Litgrid, "Litgrid." [Online] [06.03.2018]. Available at: http://www.litgrid.eu/index.php/services/service-prices/2480.

[19] "TUoS Statement of Charges," 2016. [Online] [06.03.2018]. Available: http://www.soni.ltd.uk/media/documents/Customers/TUOS/Final TUoS Statement of Charges 2016-17.pdf.

[20]Elektrilevi OÜ, "Power grid prices of Elektrilevi. Действует from 1 November 2017 (in Russian)," 2017. [Online] [29.11.2017]. Available at: https://www.elektrilevi.ee//doc/6305157/kliendile/el_hinnakiri_vorguteenused_01112017_rus.pdf. 